\title{
ROLE OF STRESS IN PROGRESSION OF MIGRAINE
}

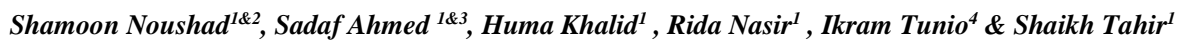 \\ 1. Health Science Research Division- AEIRC \\ 2. Dow University of Health Sciences \\ 3. University of Karachi \\ 4. Chandka Medical College \\ Corresponding Author Email: shamoon@aeirc-edu.com
}

\section{ABSTRACT}

The mental and physiological stresses can be an important trigger of migraines \& headaches. These strains act to enhance the progression of migraine that could be psychological, physiological stress, Environmental stress or Chemical stress. The population data of 185 people have taken which include the ages from 14-60 years. The data were analyzed by ICHD-II criteria .The duration of the research was from-February 2012 to December 2012.The targeted population were of both genders age ranges 18-25 years. The data have collected in two parts, before examination and during examination. The obtain result shows that the frequency of migraine is higher in women as compare to men. Mostly people were suffering from mild psychological stress that might be periodical stress as approximately $50 \%$ people were students who were under examination stress as the exams were about to held. Nutritional stress is another major factor as the high temperature causes dehydration resulted in vasoconstriction resulted in sensation of pain. Environmental stress was an additional cause for students. Physiological stress was also noticed as the main cause that bring about the initiation of migraines period whether it could also leads towards the Menstrual migraine that has a sign of vomiting or nausea. Individual concerns with healthy life patterns and stress free conditions could help a person to reduce or prevent the migraine.

\section{KEYWORDS}

Migraine, Physiological stress, Psychological stress, Environmental stress, Headache

\section{INTRODUCTION}

Photophobia and phonophobia due to Psychological or physiological changes. The exact mechanism of migraine is still unknown .CNS plays an important role and secretion of cortisol from adrenal cortex (Hussain, 2008). Pathophysiologically, stress causes the changes that result in the abnormal secretion of cortisol (Ayata, 2006). The worst scenario of migraine could commence the higher chance of heart stroke and other cardiovascular disorder whether migraine with aura could also cause mortality in men and women.

Different psychological stress that usually exposed in our daily life include load shedding, political impact lack of basic necessities ,unemployment and other socioeconomic stress participate critical role (Gervil, 1999; Holroyd, 2001) whether events like getting married or divorced, having a baby, family problems, financial pressures, study and other day to day stresses might be the sources of stress in spite of that hormonal changes ,bright light usually sun light ,physical exertion ,oversleeping, empty stomach may also bring about the initiation of migraine that results in the intense throbbing constant pain, dullness or sometimes dizziness whether environmental factor also play a crucial role (Soleimanpour, 2012; Bokhari, 2008), as the high temperature might causes dehydratic condition and nutritional deficiency that causes hypoglycemic condition due to this body tries to retain water and nutrition which brings about vascular constriction and pain which is a physiologically stressed condition (Yu, 2011; Theeler, 2010). The ratio of migraine is higher in women as compare to men and among women it is quit higher in the women who are married and episodes usually increases in pregnancy that could be because of different hormonal and physiological changes during that period as women faces different emotional and in many cases nutritional stress. The high probability of migraine in women could be because of an additional type of migraine which is menstrual migraine that can be symptomised as nausea and vomiting usually this type of migraine stops as the stage of menopause arises in women (Sauro, 2009). By the healthy life style with regular physical activity eating a healthy diet, practicing relaxation techniques, stress free environment and adequate amounts of sleep may be helpful to a person in coping up with migraine.

\section{METHODOLOGY}

In this cross-sectional study, a questionnaire based qualitative population data of 185 people was taken after taking consent from subjects to participate and the study was approved by IEC of AEIRC, Pakistan. All the subjects were in the age ranges from 1460 years of both genders were included .The inclusion and exclusion criteria is based on sensation of pain in the head, intensity of pain and other factors like duration, causes, feeling, impact, side of head where pain feels the most, family history etc. has considered to know that if a person is facing headache or migraine problem or moving towards migraine from headache. The data were collected in two parts, before examination and during examination.

The data has taken from married and unmarried, professional and unprofessional, diagnosed and undiagnosed population. The obtained results were analyzed by International classification of Headache disorder, Second Edition criteria (ICHD-II criteria) having the duration of the research from February 2012 to December 2012. 


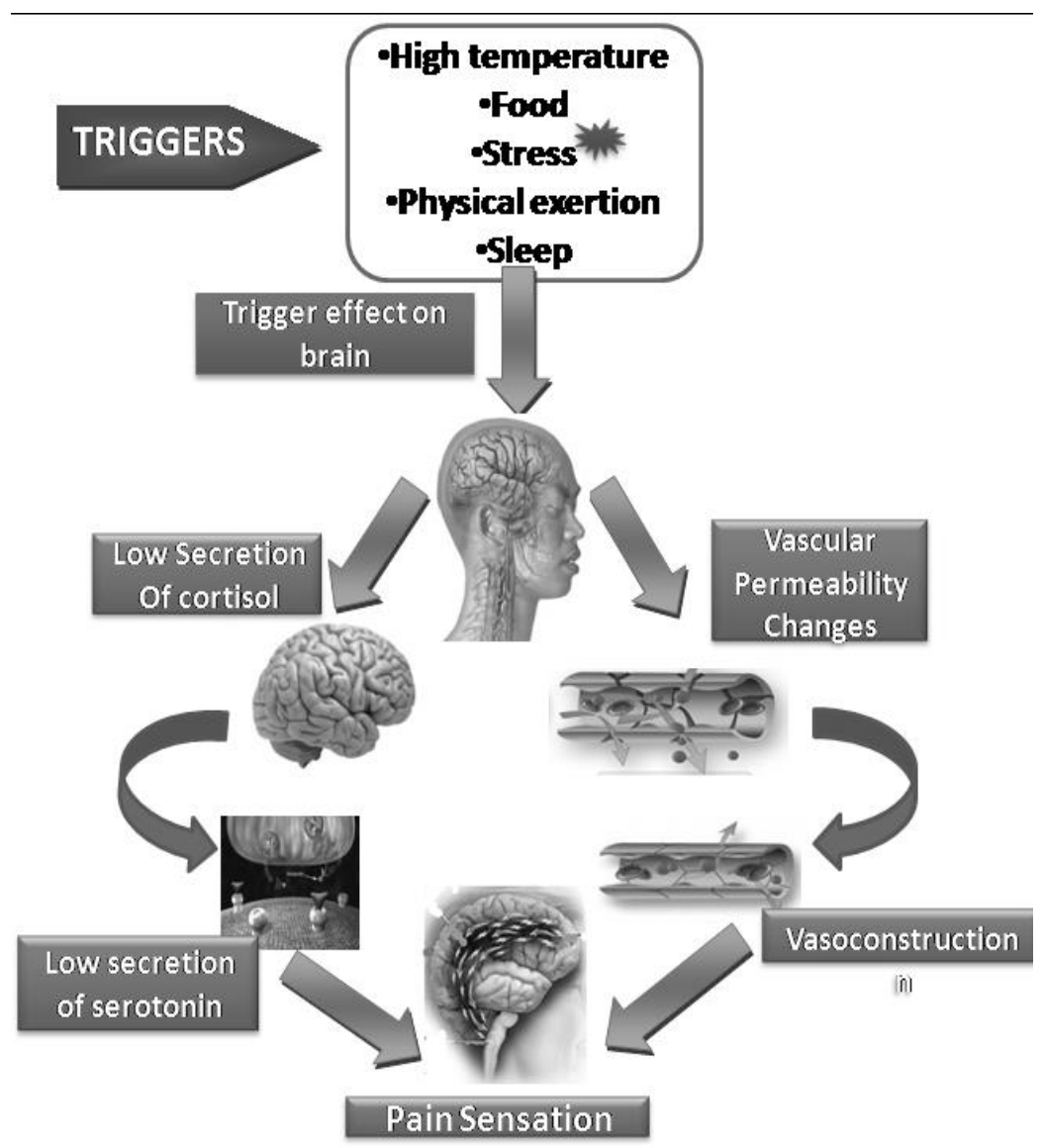

Figure.1: Showing Pathophysiology of Migraine

HOW A HEADACHE CONVERT INTO MIGRAINE?

Migraine

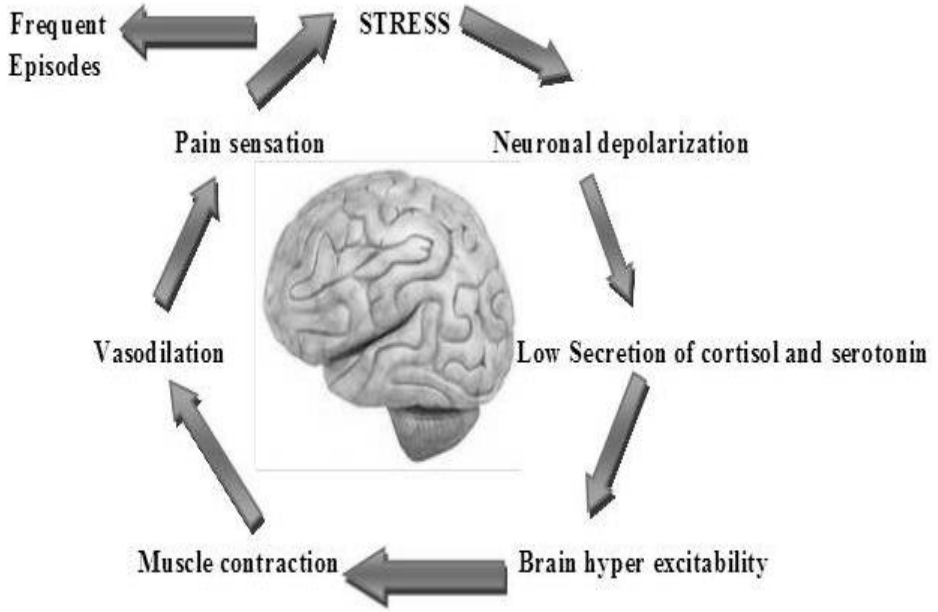

Figure .2: Showing how a Headache Lead towards Migraine 


\section{RESULTS}

The result shows that female has higher ratio of headache and migraine as compare to male. Mostly people were suffering from mild psychological stress that might be periodical stress as approximately $50 \%$ people were students who were under examination stress as the exams were about to held. Nutritional stress is another major factor as the high temperature causes dehydration resulted in vasoconstriction resulted in sensation of pain. Environmental stress was an additional cause for students. On the other side medication, taking rest, dark quite room and drinking coffee were the relieving factors.

\begin{tabular}{|c|c|c|}
\hline S. No. & Events or time where Headache-Migraine starts & $\begin{array}{l}\% \text { of the population } \\
\text { Where } n=185\end{array}$ \\
\hline 1 & Morning & 7.567 \\
\hline 2 & Evening & 37.29 \\
\hline 3 & Afternoon & 15.13 \\
\hline 4 & During Sleep & 14.59 \\
\hline 5 & During Weekends & 0 \\
\hline 6 & Beginning of week & 4.32 \\
\hline 7 & Middle of week & 8.64 \\
\hline 8 & End of week & 8.64 \\
\hline 9 & Bright light causes them & 33.51 \\
\hline 10 & During or After having sex & 0.54 \\
\hline 11 & During emotional stress & 37.83 \\
\hline 12 & After emotional stress & 23.24 \\
\hline 13 & During physical exertion & 10.8 \\
\hline 14 & After not eating several hours & 27.56 \\
\hline 15 & After napping or over sleep & 17.83 \\
\hline 16 & After drinking alcohol & 0.54 \\
\hline 17 & Before Menstrual cycle & 7.56 \\
\hline 18 & During Menstrual cycle & 5.40 \\
\hline 19 & After Menstrual cycle & 1.08 \\
\hline 20 & After bending your head downwards & 17.83 \\
\hline 21 & No Pattern & 11.35 \\
\hline
\end{tabular}

Table: Shows the Events or time when the Headache-Migraine of the sufferer started.

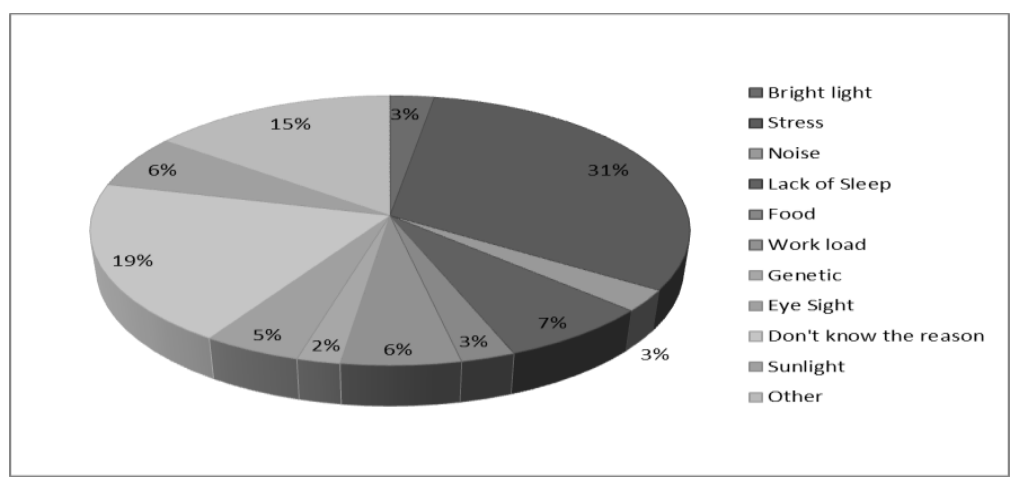

Figure No.3: Graph Show the main causes that make their headache-migraine worse. It indicates that the stress is major exaggerating factor that usually make their headache- migraine worse. 


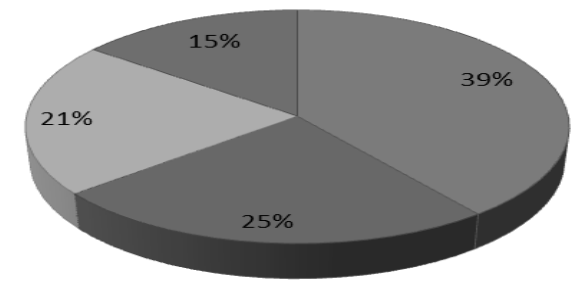

$\square$ Psychological Stress

Physiological stress

$\square$ Environmental Stress

$\square$ Genetic

Figure No.4: The graph shows different types of exerted stress that leads a person towards migraine where Psychological stress is the major cause of migraine nutritional stress is the second main cause and environmental stress is at number three

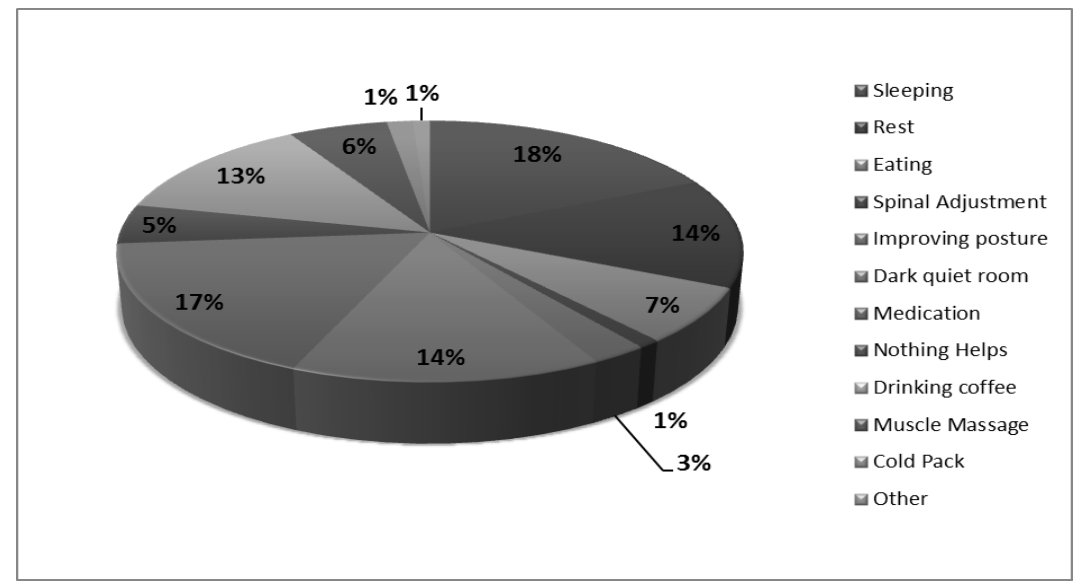

Figure No.5: The graph shows several factors that relief in Migraine include sleep, rest, eating, spinal adjustment Dark quite room etc. Graph indicates that Sleep is the main relieving factor whether medication, taking rest, dark quite room and drinking coffee also play essential role.

\section{DISCUSSION}

It was found that the women were highly susceptible to migraine as compare to Men encompasses the difference in their physiology as the women has an additional type of migraine i.e. menstrual migraine which usually begin in the stage of puberty and impede at the menopausal phase this physiological variation cause a temporary physiological stressed state whether the quotient of psychological stress is also high in women in contrast to men (Goadsby, 2002; May, 1999). The frequent episodes of stress headache instigate migraine or shift a person toward migraine as in the data higher proportion of the migraineur were found where the proportion of headache sufferer were less the reason could be at that time students were facing the stress of their examination although daily life stress, physical exertion and hot atmosphere might be the reason that rehabilitated their headache to the migraine (Sillanpää, 1983; Somerville, 1975; Stovner, 2007).

Study shows that in the targeted population exerted migraine became worse by several reasons having stress as main reason (Sauro,2008; Jes Olesen, 2006; Al-Shimmery, 2010), there were also the people who didn't know the exact cause of their pain lack of sleep, work load, sunlight, noise and food are further major reasons. An emotional stress is also the fore most important cause or event people reported a higher ratio of migraine during an emotional stress where its impact also found after an emotional stress whether pain sensation mostly found in the evening. As the work load is usually high in the middle of the week and physical stress become high in the end of the week so migraine is highly reported in these periods (Martin, 1997; Martin, 2001). Bright light and physical exertion, menstruation and hungriness initiate the physiological stress sun light is also responsible for the commencement of migraine.

We found that the psychological stress was the major type of exerted stress where nutritional stress was the second major along with the environmental stress the high fraction of this might be for the reason that maximum data were collected in the month of June and July which were the crest summer season months.

Sleep (Fukui,2008) rest, eating, dark quite room, drinking coffee and medication have proved quite helpful in curing or reliving pain 
it is found that the way people usually use is to sleep and taking rest as it permit body to return towards the normal state and control brain's hyper-excitability and return body to the normal physiology to get rid of the stressed condition but in the migraine with aura these exercises give no relief and migraine complete its duration (Welch, 1990; Jes, 2006).

\section{REFERENCES}

- Al-Shimmery, E. K. (2010). Precipitating and Relieving Factors of Migraine Headache in 200 Iraqi Kurdish Patients. Oman medical journal, 25(3), 212-217.

- Ayata, C., Jin, H., Kudo, C., Dalkara, T., \& Moskowitz, M. A. (2006). Suppression of cortical spreading depression in migraine prophylaxis. Annals of neurology, 59(4), 652-661.

- Bokhari, F. A., Sami, W., Shakoori, T. A., Ali, S. A., \& Qureshi, G. A. (2008). Clinical characteristics of 226 collegegoing female migraineurs in Lahore, Pakistan--Putting ICHD2 to the road test. Neuroendocrinology Letters, 29(6), 101-106.

- Fukui, P. T., Gonçalves, T. R. T., Strabelli, C. G., Lucchino, N. M. F., Matos, F. C., Santos, J. P. M. D., ... \& Peres, M. F. P. (2008). Trigger factors in migraine patients. Arquivos de neuro-psiquiatria, 66(3A), 494-499.

- Gervil, M., Ulrich, V., Kaprio, J., Olesen, J., \& Russell, M. B. (1999). The relative role of genetic and environmental factors in migraine without aura.Neurology, 53(5), 995-995.

- Goadsby, P. J., Lipton, R. B., \& Ferrari, M. D. (2002). Migraine - current understanding and treatment. $\mathrm{N}$ Engl $\mathrm{j}$ Med, 346(4), 257-270.

- Holroyd, K. A., O'Donnell, F. J., Stensland, M., Lipchik, G. L., Cordingley, G. E., \& Carlson, B. W. (2001). Management of chronic tension-type headache with tricyclic antidepressant medication, stress management therapy, and their combination. JAMA: the journal of the American Medical Association, 285(17), 2208-2215.

- Hussain, A. M., Mohit, M. A., Ahad, M. A., \& Alim, M. A. (2008). A study on psychiatric co-morbidity among the patients with migraine. TAJ: Journal of Teachers Association, 21(2), 108-111.

- Jes Olesen, Peter J. Goadsby, Nabih M. Ramadan, Peer TfeltHansen, K. Michael A. Welch. The headache 3rd edition by lippiccott willianms and wilkins neurology 1-1138 2006.

- Martin, P. R. (2001). How do trigger factors acquire the capacity to precipitate headaches?. Behaviour research and therapy, 39(5), 545-554.

- Martin, P. R., \& Seneviratne, H. M. (1997). Effects of food deprivation and a stressor on head pain. Health Psychology, 16(4), 310-318.

- May, A., Ashburner, J., Büchel, C., McGonigle, D. J., Friston, K. J., Frackowiak, R. S. J., \& Goadsby, P. J. (1999). Correlation between structural and functional changes in brain in an idiopathic headache syndrome. Nature medicine, 5(7), 836-838

- Sauro, K. M., \& Becker, W. J. (2009). The stress and migraine interaction.Headache: The Journal of Head and Face Pain, 49(9), 1378-1386.

- Sillanpää, M. (1983). Changes in the prevalence of migraine and other headaches during the first seven school years. Headache: The Journal of Head and Face Pain, 23(1), 15-19.
- Soleimanpour, H., Ghafouri, R. R., Taheraghdam, A., Aghamohammadi, D., Negargar, S., Golzari, S. E., \& Abbasnezhad, M. (2012). Effectiveness of intravenous Dexamethasone versus Propofol for pain relief in the migraine headache: A prospective double blind randomized clinical trial. BMC neurology, 12(1), 114-120.

- Somerville, B. W. (1975). Estrogen-withdrawal migraine I. Duration of exposure required and attempted prophylaxis by premenstrual estrogen administration. Neurology, 25(3), 239239.

- Stovner, L. J., Hagen, K., Jensen, R., Katsarava, Z., Lipton, R. B., Scher, A. I., ... \& Z Zwart, J. A. (2007). The global burden of headache: a documentation of headache prevalence and disability worldwide. Cephalalgia, 27(3), 193-210.

- Theeler, B. J., Flynn, F. G., \& Erickson, J. C. (2010). Headaches after concussion in US soldiers returning from Iraq or Afghanistan. Headache: The Journal of Head and Face Pain, 50(8), 1262-1272.

- Welch, K. M., D'andrea, G., Tepley, N., Barkley, G., \& Ramadan, N. M. (1990). The concept of migraine as a state of central neuronal hyperexcitability.Neurologic clinics, 8(4), 817-828.

- Yu, S. Y., Cao, X. T., Zhao, G., Yang, X. S., Qiao, X. Y., Fang, Y. N. \& Steiner, T. J. (2011). The burden of headache in China: validation of diagnostic questionnaire for a populationbased survey. The journal of headache and pain,12(2), 141146. 